\title{
SURVEY ON PLANT DISEASE DETECTION AND APPLIED SMART IRRIGATION SYSTEM
}

\author{
1. Prof. M.M. Baig \\ 2. Chitra Bhujade 3. Dikshita Tambe, \\ 4. Harshada Mohinkar 5. Pratiksha Tandekar 6. Vanashri mohurle \\ Scholar (3rd year) Department of Computer Science and Engineering J D College of Engineering and \\ Management, Nagpur, India \\ likechitra2016@gmail.com \\ dikshitabtambe@gmail.com \\ harshadamohinkar11@gmail.com \\ tandekarpratiksha60@gmail.com \\ vanashrimohurle12@gmail.com \\ mirzammb@gmail.com
}

DOI: $10.51201 / J U S S T / 21 / 05160$

http://doi.org/10.51201/JUSST/21/05160

\begin{abstract}
In today's era farmers have been facing many problems related to climate change, more production of crops. some times plants can become weak by some diseases, and farmers can not be aware of their plant's growth. To check on the internet of things, the concept helps us to interconnect physical objects equipped with sensing, actuating, computing power and thus lends them the capability to collaborate on a task in unison remaining connected to the internet termed as the IoT. It is placed on the farm field and detects the disease and gives notification to farmers related to the disease on plant leaves and also suggests how to overcome that problem. Farmer also can know about climate conditions before a weak or 2 or 3 days. Wireless sensor network (WSNs) acquisition device, environment user-interfaces, and low-cost monitoring system for detecting the various disease in agriculture and farming domain use innovative of automatic learning decision support are proposed to manage the disease detection system. thus, in this paper, future the need to use technology in the agriculture field is easy to know about the climate condition before one month and the growth or health of the plant.
\end{abstract}

\section{Keywords - Machine Learning, Crop monitoring, weather API, OpenCV.}

\section{INTRODUCTION}

THIS quick development of the web of things(IoT) technologies supposed researchers and developers to suppose new types of smart services that extract knowledge from IoT-generated data. Agriculture is that the backbone of the Indian economy. the most business of Indian people fifty nothing population depends on agriculture. In 1995 "thing to issue " was coined by entrepreneurs, in 1999, IoT (internet of things) was return up by EPC international. The EPC international Network might be a network acquainted with sharing product data between commerce partners. it absolutely was created by EPC international. the premise for the info flow inside the network is that the Electronic Product Code (EPC), EPC is additionally encoded terribly\} very Frequency Identification (RFID) tag, however, is not designed fully to be used with RFID data carriers. agriculture science has been operative to evolve technologies in farming the foremost issue moving to a farm is international temperature change, nature of the soil, increment, cuss $\&$ diseases. In today's Era the foremost issue inside the agriculture field whether or not or not \& climate risk. the management of weather and 
climate risk in agriculture has become an important issue because of international temperature change. sheep prediction to all or any or any blocks across \& districts inside the country by 2020 and helps as many as 9.5 core farmers cope with the vagaries of weather this paper could be a trial to ascertain the numerous cubic centimetre moreover as IoT techniques applied to the agriculture sector to predict soil condition, weather and various factors moving agriculture. we use the IoT is to sense the gathered data from shut moreover as perform a self-activating perform for the user. IoT in environmental looking helps to know relating to the air and water quality temperature and conditions of the soil and put together monitor the intrusion of animals into the fields. the system uses two footage information one for the work of already keep infected house and completely different for the execution of question image. the project presents disease victimization Associate in Nursing open cv camera system used within the agriculture field. the agriculture analysis of automatic disease sightion is crucial in looking large fields of crops and automatically detect the diseases. OpenCV (Open offer portable computer Vision) might be a library of programming functions within the main aimed toward amount portable computer vision. this project aims to observe diseases on plant ANd suggest an improved resolution for healthy yield and productivity of the plant .

\section{AWARENESS}

To increase information and awareness among farmers to boost the assembly and productivity of assorted crops. To extend information and awareness among farmers to boost the assembly and productivity of assorted crops, the govt of Bharat has initiated varied programmers like Extension through Considering the figures for water crises around the globe, same time its increasing demands in agriculture and plenty of different industries, it ought to be provided to places solely wherever it's required, most significantly, within the needed quantities. For this purpose, enhanced awareness has been enforced to conserve the present under-stress water resources by using additional economical irrigation systems. The history of agricultural development in Bharat shows that Indian Agriculture was unable to feed the forty-five corers. currently, within the twenty-first Century, Bharat will feed its population of quite a hundred corers providing raw materials for consumer goods and industrial functions once an affordable quantity of export. so there's a Brobdingnagian increase within the production aspect in several agricultural commodities however there's no more positive of this within the level of living of farmers.

\section{OBJECTIVE}

The objective of this analysis paper is to propose IoT primarily based sensible Stick which can modify farmers to own live data of soil moisture, setting the temperature at a really low value so that live observance will be done the objective of this paper is to propose a unique sensible IoT primarily based Agriculture which assisting farmers in getting Live information (Temperature, Soil Moisture) for economical setting observance which can modify them to do sensible farming and increase their overall yield and quality of merchandise .

\section{TOOLS AND DATA COLLECTION}

Tools and information assortment Following are the tools and information that we've to attain our framework is as In what follows, we will we'll we are going to place the spotlight are Incorporating the climatically Parameters The weather-based controller additionally called evaporate transpiration controller. On a routine, a lookout or remote weather service monitors conditions like temperature, wind, and wetness. The sensible irrigation controller is soil sensors based mostly business within the root zone of turf plants live the wet level within the soil and transmit this information to the controller These work with high-quality weather sensors, that receive period weather updates and use an equivalent for customizing the irrigation events. Message causing module: APIs for farming, helps to appear at what variety of diseases that plant. whereas genus Apes will trot out a wide-ranging set of information, most farming genus Apes are involved with international information, Regional information, and native information. Database: illustrative pictures of plant diseases particularly helps the professionals committed to agricultural 
production, as they typically stumble upon plant health issues. The info was additionally created to become a reference for the event of ways to discover and mechanically acknowledge plant diseases. Arduino microcontroller: In Associate in Nursing automatic plant watering system or we will say it sensible irrigation system. we tend to area are unit square live mistreatment Associate in Nursing Arduino microcontroller to manage and sense the factor within the comes like sense or measure the wet within the soil we tend to are mistreatment soil wet detector. Specialized camera: should be able to see live what's happening at the farm by open cv additionally able to access a live icon of detected intrusions from anyplace employing a portable. The project presents plant disease identification mistreatment image process techniques for the machine-driven vision system utilized in the agricultural field. The projected decision-making system utilizes image content characterization and supervised classifier kind back propagation with a feed-forward neural network.

\section{RESEARCH METODOLOGY}

To enhance the productivity of the crop thereby supporting each farmer and nation we've to use the technology that estimates the standard of crop and giving suggestions

Some disadvantages in communication $\times$ should be overcome by advancing the technology to consume less energy and conjointly by creating the computer program easy use

1. Sensors:wetness Sensor:- Soil wetness sensors live the water content within the soil. A

soil wetness probe is created from multiple soil wetness sensors. One common variety

of soil wetness sensing elements in business use could be a frequency domain sensing element like a

capacitance sensor

2. Temperature and wetness Sensor:-You will live temperature a lot of accurately than employing a semiconductor device. The sensing element electronic equipment is sealed and not subject to reaction, etc. The LM35 generates a better output voltage than thermocouples and should not need that the output voltage be amplified

3. Water level Sensor:-Water level sensors $\times$ square measure accustomed sight the extent of drugs which will flow. it's accustomed indicate the optimize the extent of water knowledge the info the information mining technique was applied to research the obtained data for predicting the acceptable temperature, humidity, and soil wetness of crops within the future arrange.

4. The wetness content within the soil was appropriate for the vegetables to be born-again with excellent care reducing prices and increasing agricultural productivity. Moreover, this work is going to be helpful to farmers or those curious about agriculture driving by innovation.

5. Software: specialized code solutions that concentrate on specific farm varieties or use case agnostic IoT platforms \& Windows nongovernmental organization

6. Connectivity: MySQL \& Server

Location: GPS, Geotagging

Technology: Open CV, IoT, JavaScript, Ionic, MySQL.

Smart systems accustomed comprehend the health and growth of plants conjointly take the assistance of prediction as a result of farmers can comprehend before one month the weather or climate condition of when one month.

\section{PROCESS DESCRIPTION}

The camera we can place on the farm. the placed camera captures the captured image using an open cv plant. That plant can have some diseases by the movement of insects on the plant. that image can compare with an image that can already in the database.

And that notification can give to the farmer by the application that are we make the name of the disease and how to overcome that disease means the solution can over there by the application .because of that application farmer also know about the climate condition. if after one month the whether can Sunny or rainy that app can also give the information of climate condition. 


\section{ALGORITHM SURVEY}

\section{1) K-Mean Algorithm :}

- Advantages : 1)Generalizes to clusters of different shapes and sizes, such as elliptical clusters. 2)Choosing manually.

- Disadvantages
1)Difficult
to
predict
K-Value.

2)With global cluster, it didn't work well

We can not use the k-mean algorithm in our project because this algorithm is used to bifurcate the images.

\section{2) Numpy Pip 3 Algorithm:}

- Advantages : One of the main advantages of using Numpy arrays is that they take less memory space and provide better runtime speed when compared with similar data structures in python(lists and tuples).

- Disadvantages : NumPy itself supports "nan" but lack of cross-platform support within Python makes it difficult for the user

We can't used the num py pip 3 algorithm in our project because that algorithm are generally used to manage the in mobile but we are used the cloud computing in our project so no need to use the that algorithm.

\section{3) FLOW CHART}

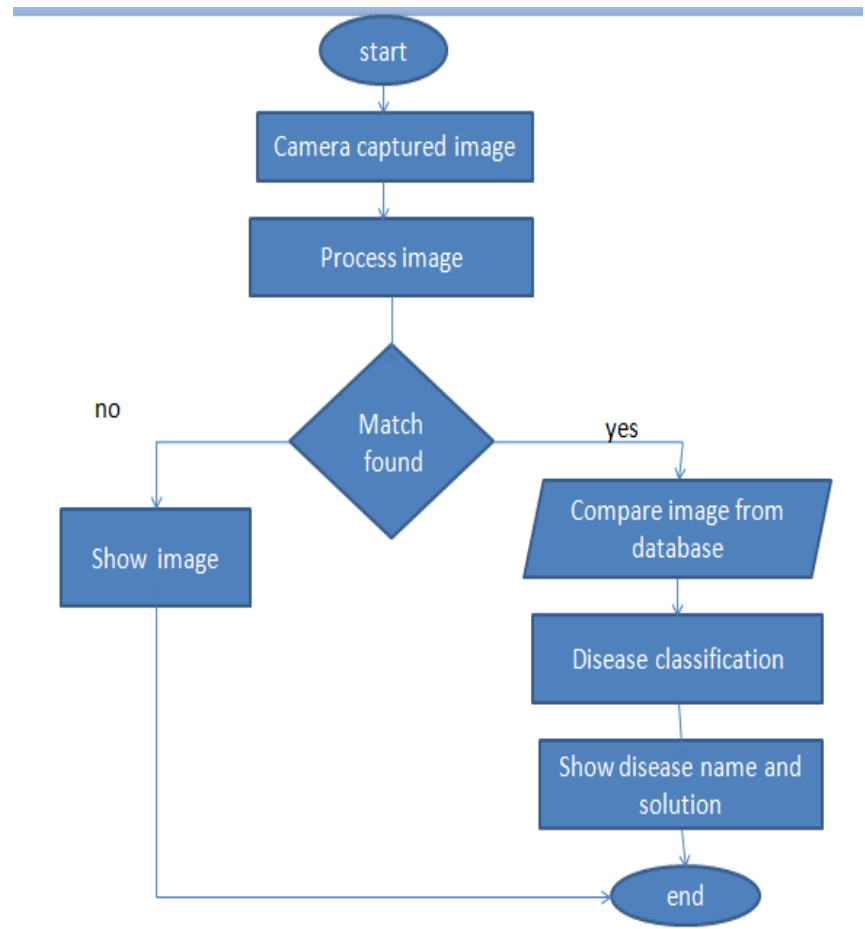

(a) 


\section{4) FUTURE SCOPE}

Future work would be centered additional on increasing sensors on this method to fetch additional knowledge particularly regarding pesterer management and by conjointly group action GPS module during this system to boost this Agriculture IoT Technology to full-fledged Agriculture preciseness prepared product.

\section{5) REFERENCES}

1. Wijitdechakul, J., Kiyoki, Y., Sasaki, S.and Koopipat, C. "A Multispectral Imaging and Semantic Computing System for Agricultural Monitoring and Analysis" Information Modelling and Knowledge Bases XXVIII (2017).

2. Kiyoki, Y., Chen, X., Sasaki, S.and Koopipat, C. "A Globally-Integrated Environmert Analysis and Visualization System with Multi-Spectral \& Semantic Computing in Multi-Dimensional World Map," Information Modelling and Knowledge Bases XXVIII (2017).

3. Kiyoki, Y., Chen, X., Sasaki, S.and Koopipat, C. "Multi-Dimensional Semantic Computing with SpatialTemporal and Semantic Axes for Multi-spectrum Images in Environment Analysis," Information Modelling and Knowledge Bases XXVII (2016), pp. 27-47.

4. De Biasio, M., Arnold, T. and Leitner, R. "UAV based Multi-spectral Imaging System for Environmental Monitoring," Proceedings of The International Society for Optical Engineering (2011), pp. 503-507

5. Rouse, J. W., Hass, R. H., Schell, J. A. and Deering, D. W. "Monitoring vegetation systems in the Great Plains with ERTS," Third ERTS Symposium, NASA SP-351 I(1973), pp.309-317.

6. McFeeters, S. K. "The use of Normalized Difference Water Index (NDWI) in the delineation of open water features," International Journal of Remote Sensing (1996), pp.1425-1432.

7. Huete, A.R. "A soil-adjusted vegetation index (SAVI)" Remote Sensing of Environment(1998), vol. 25, pp. 259309.

8. Kiyoki, Y., Kitagawa, T. and Hayama, T., "A metadatabase system for semantic image search by a mathematical model of meaning," ACM SIGMOD Record(1994), Vol.23, No. 4, pp.34-41

9. Kiyoki, Y. and Kitagawa, T., "A semantic associative search method for knowledge acquisition," Information Modelling and Knowledge Bases VI (1995), pp. 121-130. 10. Chen, X. and Kiyoki, Y., "A Visual and Semantic Image Retrieval Method Based on Similarity Computing with Query-Context Recognition," Information Modelling and Knowledge Bases XVIII (2007), pp. 245-252.

11. Lee, Brendon (2015-07-20). "Sci Dev Net; South East Asia \& Pacific". SciDev.net. Retrieved 21 July 2015.

12. Hou-Ping W., Ping L., Yu W., Ying-Wei H. and Cheng L. "Measurement for opto-electronic conversion functions (OECFs) of digital still-picture camera" SPIE Proceedings Vol. 7850 (2010)

13. A. ARDESHIR GOSHTASBY., "2-D and 3-D Image Registration: for Medical, Remote Sensing, and Industrial Applications" ISBN: 978-0471-64954-0, 284 pages (Feb, 2005).

14. Edward A. Lee, "Cyber Physical Systems: Design Challenges," Object Oriented Real-Time Distributed Computing (ISORC), 11th IEEE International Symposium on 5-7 May, 2008, pp. 363-369.

15. Ragunathan (Raj) Rajkumar, Insup Lee, Lui Sha, John Stankovic, "Cyber-Physical Systems: The Next Computing Revolution", DAC '10 Proceedings of the 47th Design Automation Conference, ACM New York, NY, USA, 2010, Pages 731-736, 2010.

16. Shiori Sasaki, Yasushi Kiyoki, "Real-time Sensing, Processing and Actuating Functions of 5D World Map System: A Collaborative Knowledge Sharing System for Environmental Analysis", IOS press, SeriesFrontiers in Artificial Intelligence and Applications, Volume 280: Information Modelling and Knowledge Bases XXVII, pp. 220 - 239, DOI10.3233/978-1-61499-611-8-220, 2016.

17. Cloud Computing Assisted Blockchain-Enabled Internet of Things Chao Qiu, Student Member, IEEE, Haipeng Yao, Member, IEEE, Chunxiao Jiang, Senior Member, IEEE, Song Guo, Senior Member, IEEE, and Fangmin Xu. This is a resubmitted manuscript, which is approved by the EIC.

18. S. Gartner, "Forecast: The internet of things, worldwide, 2013," 2013. 
19. W. Li, T. Logenthiran, V. Phan, and W. L. Woo, "Implemented IoTbased self-learning home management system (SHMS) for singapore," IEEE Internet of Things Journal, vol. 5, no. 3, pp. 2212-2219, June 2018.

20.W. Chin, W. Li, and H. Chen, "Energy big data security threats in iot-based smart grid communications," IEEE Comm. Mag., vol. 55, no. 10, pp. 70-75, OCTOBER 2017. 